\title{
Serum Alpha-Fetoprotein, Triglyceride, and Total Cholesterol among Sudanese Patients with Non-Alcoholic Fatty Liver Disease
}

\author{
IbrahimY.Ibrahim ${ }^{1}$, Husham O. Elzein ${ }^{1}$, NassrEldin M.A.Shrif ${ }^{2}$, \\ AmnaO.M.Elzein ${ }^{2 *}$,AbdelgadirEltom ${ }^{3}$ \\ ${ }^{1}$ Faculty of medical laboratory science, University of science and technology, Omdurman, Sudan \\ ${ }^{2}$ Department of clinical chemistry, faculty of Medical laboratory Sciences, Al zaiem Al Azhari University-Sudan. \\ ${ }^{3}$ Medical Laboratories department, college of allied health sciences, Gulf Medical University, Ajman, UAE.
}

\begin{abstract}
Background/Aim: Non-alcoholic fatty liver disease (NAFLD) refers to the accumulation of hepatic steatosis not due to excess alcohol consumption.It is the most common liver condition in the world.The prevalence of NAFLD is up to $30 \%$ in developed countries and nearly $10 \%$ in developing nations. The aim of this study is to assess serum alpha-fetoprotein triglyceride, and total cholesterolamong Sudanese with non-alcoholic fatty liver disease.

Methods:This is a descriptive cross sectional study was conducted in Advance diagnostic center, Bahary hospital, Khartoum state, Sudan during the period of Sep 2016 to Nov 2016. Participants were divided into two groups; patient group (N/40), and non-alcoholic fatty liver disease NAFLD, and 40 normal individual as control group. Triglyceride, total cholesterol were measured by using spectrophotometric method, while alphafetoprotein measured byusing enzyme immune assay test ELISA.

Results: The current study revealed that there is significant difference in triglyceride $(T G)$ and alpha fetoprotein (AF) between cases and control group $(P=0.000)$, and $(P=0.004)$ respectively, however insignificant in total cholesterol $(T C),(P=0.629)$. The study also showed strong positive correlation between $T G$ and AFP $(R$ value $(+0.527),(P=0.00)$. Age showed negative correlation with AFP $R$ value $(-0.316),(P=0.047), T C$ and $A F P$ showed no correlation $R$ Value $(+0.246),(P=0.126)$.

Conclusion: Patients with NAFLD have higher AFP levels and TG than those without fatty liver changes. AFP levels rise as grade of liver steatosis increases.
\end{abstract}

Keywords:Nonalcoholic fatty liver disease, Alpha-fetoprotein,Triglyceride, Cholesterol

\section{Introduction}

Nonalcoholic fatty liver disease (NAFLD) is a very common disorder, and one of themajor cause of cirrhosis in the western world [1],it is mainly associated with obesity and metabolic disorders [2].Obesityand NAFLD has become an epidemic around the world, in the United States of America 30\% or more of the adults are affected by NAFLD [3], and scored a high prevalence about 20\% in China [4].Although NAFLD may remain asymptomatic, it also may insidiously progress to cirrhosis and end stage liver disease[5, 6], as well as it characterized by steatosis, inflammation, and considered as one of the major cases of hepatocellular carcinoma (HCC) $[7,8,9,10]$. Alpha-fetoprotein (AFP) is a glycoprotein [11], that is normally formed during conception by the fetal liver and yolk sac(1-2 months), and subsequently predominantly in the liver ,In clinical practice, AFP levels are increased in many clinical events, such ashepatocellular carcinoma, acute or chronic viral hepatitis, chronic liver disease [12, 13]. AFP is a well-established tumor marker for HCC, and recent studies have explored the potential association between AFP and NAFLD who were diagnosed by ultrasonography. [11, 14] .In this study, we evaluated serum AFP, triglyceride, and total cholesterol levels, in NAFLD patients in comparison with normal subjects.

\section{Material and Methods}

Patients: This is a cross sectional study was conducted in Advance diagnostic center, Bahary hospital, Khartoum state, Sudan during the period of Sep 2016 to Nov 2016. Participants (N/80) were divided into two groups; patient group (N/40), non-alcoholic fatty liver disease NAFLD as case and 40 normal individual as control group.Both groups were age matched, range from 27 to 84 years old with mean of 48.95 years. Patient with Liver disorder other than NAFLD, and patients with Testicular cancer were excluded from this study. After signing an informed consent, the demographic and clinical data was taken from each group (case and control) using questionnaire.

$5 \mathrm{ml}$ of venous blood was collected under septic condition in a plain blood container and centrifuged for 15 minutes at 3000rpm; serum was separated and stored in -20 till the assay of Triglyceride, total cholesterol 
Serum alpha-fetoprotein, triglyceride, and total cholesterol among Sudanese patients with non-..

which measured by using spectrophotometric method, while alpha-fetoprotein measured byusing enzyme immune assay test ELISA.

Statistical analysis:Data were entered into a computer and analyzed by using SPSS for windows (version 16.0). Data was presented as mean \pm S.D,followed by $t$.test. The results were expressed in the form of tables and figures. $P$ value of $<0.05$ was considered significant.

\section{Ethics}

Ethical clearance was obtained from the research board at the Faculty of medical laboratory science,AlzaiemAlazhari University.

\section{Results}

In this study we studied 80 participants $40(50 \%)$ case and $40(50 \%)$ control, their age range from 27 to 84 years old with mean of 48.95 years. 24 (30\%) of the participants were male and 56(70\%) were female. Table (2).The current study revealed that there is significant difference in triglyceride(TG) and alpha fetoprotein (AF) between cases and control group $(\mathrm{P}=0.000)$, and $(\mathrm{P}=0.004)$ respectively, however insignificant in total cholesterol (TC), $(\mathrm{P}=0.629)$. The Pearson correlation test Figure (1) showed that there is strong positive correlation between TG and AFP $(\mathrm{R}$ value $(+0.527),(\mathrm{P}=0.00)$, Figure $(2)$ conversely Age showed negative correlation with AFP R value $(-0.316),(P=0.047)$, when the TC and AFP Figure (3) showed no correlation $\mathrm{R}$ Value $(+0.246),(\mathrm{P}=0.126)$.

Table (1) showcomparison of mean(SD \pm ) of TC, TG and AFP in NAFLD and control groups:

\begin{tabular}{|c|c|c|c|}
\hline Variables & Case & Control & P value \\
\hline TC & $152.18 \pm 44.344$ & $156.25 \pm 29.192$ & 0.629 \\
\hline TG & $140.90 \pm 66.967$ & $98.80 \pm 29.340$ & 0.000 \\
\hline AFP & $4.7450 \pm 2.06012$ & $3.6500 \pm 1.05490$ & 0.004 \\
\hline
\end{tabular}

- $\quad t$-test was used to calculate P value.

- $\quad$ P value less than 0.05 considered significant.

Table (2) shows statistics and mean differences of TC, TG and AFP among male and female in NAFLD:

\begin{tabular}{|l|l|l|l|}
\hline Study groups & Male & Female & P value \\
\hline TC & $125.08 \pm 39.156$ & $163.79 \pm 41.829$ & 0.01 \\
\hline TG & $151.75 \pm 88.661$ & $136.25 \pm 56.572$ & 0.509 \\
\hline AFP & $4.9500 \pm 2.61482$ & $4.6571 \pm 1.82156$ & 0.686 \\
\hline
\end{tabular}

- $\quad t$-test was used to calculate $\mathrm{P}$ value.

- P value less than 0.05 considered significant.

Figure (1) shows correlation of AFP with TG in case group:

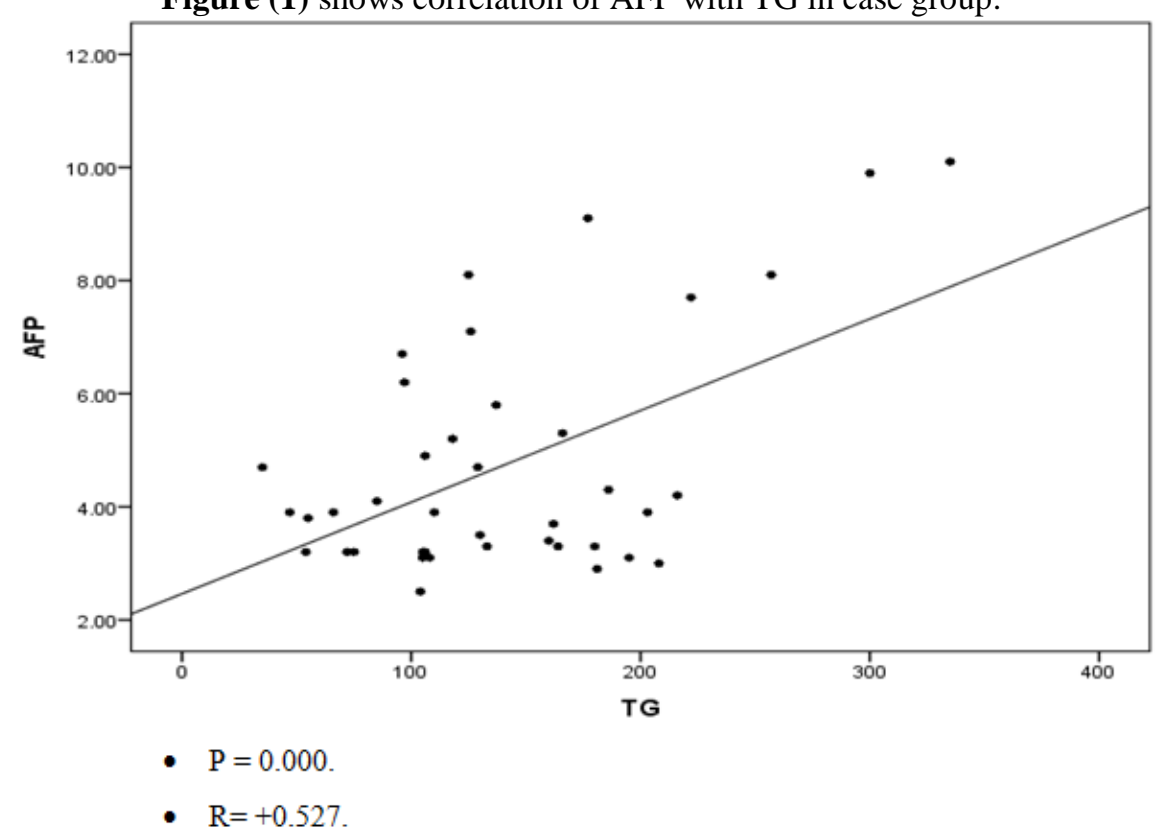


Figure(2) shows correlation of AFP with age in case group:

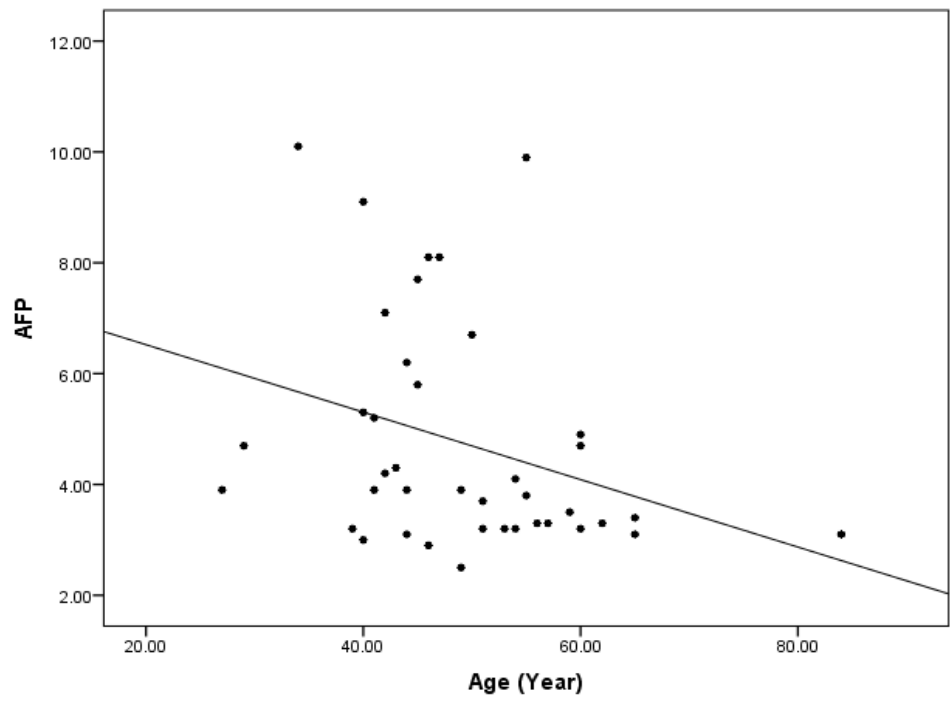

- $\quad$ P value 0.047

- $\quad$ R -0.316

Figure (3)Correlation of AFP with TC in case group:

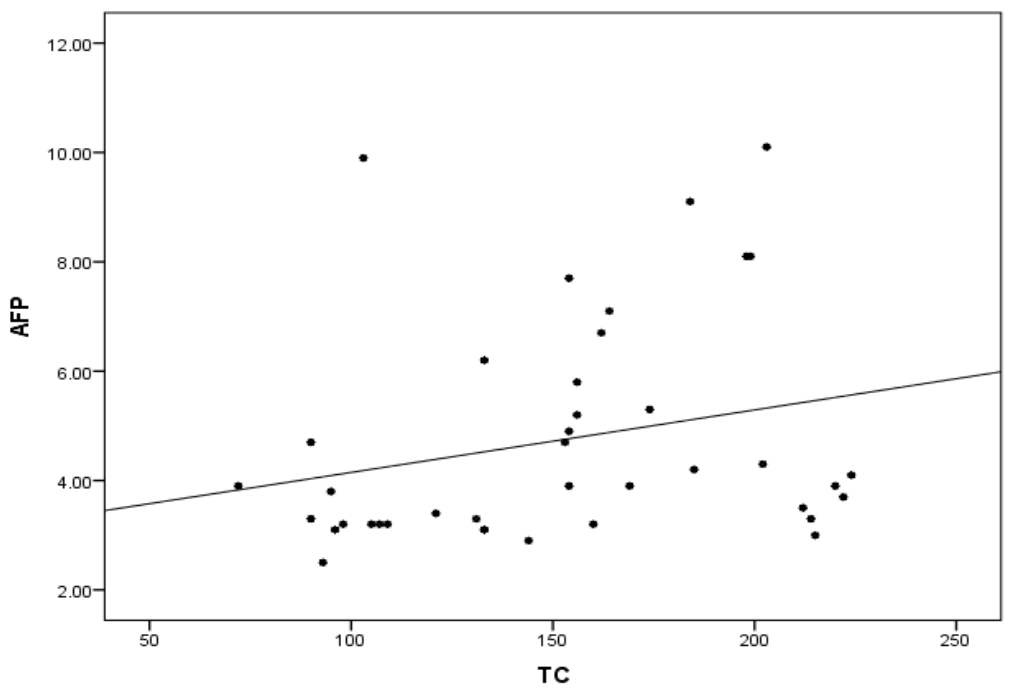

- $\quad \mathrm{P}=$ value 0.126 .

- $\mathrm{R}=+0.246$.

\section{Discussion}

In this study, we aimed to investigate the serum AFP level among Nonalcoholic fatty liver disease (NAFLD), Sudanese population, in Khartoum state from September to November 2016. The resultsrevealed a significant increase in AFP among case $(4.7450 \pm 2.06012)$, control(3.6500 \pm 1.05490$)(\mathrm{P}=0.004)$ and this may due to hepatic inflammation, steatosis, and/or fibrosis. Triglyceride (TG) also showed significant increase among case (140.90 \pm 66.967$)$, compared with control $(98.80 \pm 29.340),(\mathrm{P}=0.000)$, this result most probably due to an imbalance between lipid acquisition and removal. Total cholesterol (TC) showed non-significant increase case $(152.18 \pm 44.344)$,when control $(156.25 \pm 29.192),(\mathrm{P}=0.629)$, this matched with study done by Ays, egu" Babalı et al (2009).[16], Ping Xu et al(2014)[15] and Yimin Chen et al(2016).[17] and disagreed with M. KARA et al2013)[11],this discrepancy may be due to sample size, environmental condition, and genetic variation. The main limitation of the study was the lack of histopathological confirmation of the patients' diagnosis, noteworthy that although ultrasonography has a positive predictive value in the diagnosis of NAFLD which is around $80-100 \%[18]$, a sensitivity of $67 \%$ and a specificity of $77 \%$ have also been reported[19], in addition,to our knowledge that the diagnostic value of ultrasound decreases in obese patients. 
Serum alpha-fetoprotein, triglyceride, and total cholesterol among Sudanese patients with non-..

\section{V.Conclusions}

Patients with NAFLD have higher AFP levels, TG than those without fatty liver changes. AFP levels rise as grade of liver steatosis increases. More future work is required to know further about the pathogenesis of this condition and to establish an effectivetreatment.

\section{Acknowledgement}

Authors would like to thank all the participants and appreciate their role in this study.

Fund: None of the authors received fund.

\section{Reference}

[1]. Clark JM. The epidemiology of nonalcoholic fatty liver disease in adults. J ClinGastroenterol 2006; 40(Suppl 1):S5-S10

[2]. Chalasani N, Younossi Z, Lavine JE, Diehl AM, Brunt EM, Cusi K, Charlton M, Sanyal AJ. The diagnosis and management of nonalcoholic fatty liver disease: practice Guideline by the American Association for the Study of Liver Diseases, American College of Gastroenterology, and the American Gastroenterological Association. Hematology. 2012; 55:2005-2023. [PubMed]

[3]. Williams CD, Stengel J, Asike MI, Torres DM, Shaw J, Contreras M, Landt CL, Harrison SA. Prevalence of nonalcoholic fatty liver disease andnonalcoholic steatohepatitis among a largely middle-aged population utilizing ultrasound and liver biopsy: a prospective study. Gastroenterology. 2011; 140:124-131. [PubMed]

[4]. Wong VW. Nonalcoholic fatty liver disease in Asia: a story of growth. J GastroenterolHepatol. 2013; 28:18-23. [PubMed]

[5]. DAM-LARSEN S, FRANZMANN MB, CHRISTOFFERSEN P, LARSEN L, BECKER U, BENDTSEN F. Histologicalcharacteristicsandprognosisinpatientswithfatty liver. Scand J Gastroenterol 2005; 40:4 60-467.

[6]. BJÖRNSSON E, ANGULO P.Non-alcoholicfattyliver disease.ScandJGastroenterol2007, 42:10231030.

[7]. Wilkins T, Tadkod A, Hepburn I, Schade RR. Nonalcoholic fatty liver disease: diagnosis and management. AmFam Physician [Internet]. 2013; 88(1):35-42. Available from: http://www.aafp.org/afp/2013/0701/p35.pdf\%5Cnhttp://www.ncbi.nlm.nih.gov/pubmed/23939604\%5Cnhttp://www.aafp.org/afp/20 13/0701/p35.pdf

[8]. Shin JW, Chung YH. Molecular targeted therapy for hepatocellular carcinoma: current and future. World J Gastroenterol 2013; 19: 6144-6155 [PMID: 24115810 DOI: 10.3748/wjg.v19.i37.6144]

[9]. El-Serag HB. Hepatocellular carcinoma. N Engl J Med 2011; 365: 1118-1127 [PMID: 21992124 DOI: 10.1056/NEJMra1001683]

[10]. Starley BQ, Calcagno CJ, Harrison SA. Nonalcoholic fatty liver disease and hepatocellular carcinoma: a weighty connection. Hepatology. 2010; 51:1820-1832. [PubMed]

[11]. Kara M, Genc H, Tapan S, Meral C, Ercin CN, Erdal M, et al. Alpha fetoprotein levels and its relationship with histopathological findings in patients with non-alcoholic fatty liver disease. Eur Rev Med Pharmacol Sci. 2013; 17(11):1536-41.

[12]. Collier J, Sherman M. Screening for hepatocellular carcinoma. Hepatology 1998; 27:273-278

[13]. Journal C, Biology M. : Structure and Function. $2010 ;($ 5):299-320

[14]. Babalı A, Cakal E, Purnak T, Bıyıkoğlu I, Cakal B, Yüksel O, Köklü S. Serum $\alpha$-fetoprotein levels in liver steatosis. Hepatol Int. 2009; 3:551-555. [PMC free article] [PubMed]

[15]. Xu P, Xu C-F, Wan X-Y, Yu C-H, Shen C, Chen P, et al. Association between serum alpha-fetoprotein levels and fatty liver disease: a cross-sectional study. World J Gastroenterol [Internet]. 2014; 20(33):11865-70. Available from: http://ovidsp.ovid.com/ovidweb.cgi?T=JS\&PAGE=reference \&D=medl\&NEWS=N\&AN=25206293

[16]. Baball A, Çakal E, Purnak T, BIyIkoğlu I, Çakal B, Yüksel O, et al. Serum $\alpha$-fetoprotein levels in liver steatosis. Hepatol Int. 2009; 3(4):551-5.

[17]. Chen Y, Zhao Y, Feng L, Zhang J, Zhang J, Feng G. Association between alpha-fetoprotein and metabolic syndrome in a Chinese asymptomatic population: a cross-sectional study. Lipids Health Dis [Internet]. 2016;15(1):85. Available from: http://www.pubmedcentral.nih.gov/articlerender.fcgi?artid=4848775\&tool=pmcentrez\&rendertype=abstract

[18]. Dowman JK, Tomlinson JW, Newsome PN. Pathogenesis of non-alcoholic fatty liver disease. Qjm [Internet]. 2010; 103(2):71-83. Available from: http://www.qjmed.oxfordjournals.org/cgi/doi/10.1093/qjmed/hcp158

[19]. Chacko KR, Reinus J. Extrahepatic Complications of Nonalcoholic Fatty Liver Disease. Clin Liver Dis [Internet]. 2016; 20(2):387401. Available from: http://dx.doi.org/10.1016/j.cld.2015.10.004 